\title{
Pulmonary function in patients surviving to COVID-19 pneumonia
}

\author{
Alessia Fumagalli ${ }^{1}$ - Clementina Misuraca ${ }^{1} \cdot$ Achille Bianchi $^{1} \cdot$ Noemi Borsa $^{1} \cdot$ Simone Limonta ${ }^{2}$. Sveva Maggiolini ${ }^{1}$. \\ Daniela Rita Bonardi ${ }^{1} \cdot$ Andrea Corsonello $^{3} \cdot$ Mirko Di Rosa $^{3} \cdot$ Luca Soraci $^{3} \cdot$ Fabrizia Lattanzio $^{4}$ - Daniele Colombo ${ }^{1}$
}

Received: 16 May 2020 / Accepted: 28 June 2020 / Published online: 28 July 2020

(c) Springer-Verlag GmbH Germany, part of Springer Nature 2020

\begin{abstract}
Purpose The aim of our study was to assess respiratory function at the time of clinical recovery and 6 weeks after discharge in patients surviving to COVID-19 pneumonia.

Methods Our case series consisted of 13 patients with COVID-19 pneumonia.

Results At the time of clinical recovery, FEV1 $(2.07 \pm 0.72 \mathrm{~L})$ and FVC $(2.25 \pm 0.86 \mathrm{~L})$ were lower compared to lower limit of normality (LLN) values $(2.56 \pm 0.53 \mathrm{~L}, p=0.004$, and $3.31 \pm 0.65 \mathrm{~L}, p<0.001$, respectively), while FEV1/FVC $(0.94$ \pm 0.07 ) was higher compared to upper limit of normality (ULN) values $(0.89 \pm 0.01, p=0.029)$. After 6 weeks pulmonary function improved but FVC was still lower than $\operatorname{ULN}(2.87 \pm 0.81, p=0.014)$.

Conclusion These findings suggest that COVID-19 pneumonia may result in clinically relevant alterations in pulmonary function tests, with a mainly restrictive pattern.
\end{abstract}

Keywords COVID-19 $\cdot$ Pneumonia $\cdot$ Spirometry

\section{Introduction}

The spread of COVID-19 has taken on pandemic proportions, affecting more than 6,5 million people and causing almost 400,000 deaths worldwide [1].

Fever, fatigue, cough and expectoration are the most frequent presenting symptoms, but muscle soreness, anorexia, chest tightness, dyspnea, nausea, vomiting, diarrhea, headache also occurred frequently. The majority of patients

Electronic supplementary material The online version of this article (https://doi.org/10.1007/s15010-020-01474-9) contains supplementary material, which is available to authorized users.

Andrea Corsonello

a.corsonello@inrca.it

1 Respiratory Unit, IRCCS INRCA (Italian National Research Centre On Aging), 23880 Casatenovo, LC, Italy

2 Radiology Unit, S. Leopoldo Mandic Hospital, 23807 Merate, LC, Italy

3 Unit of Geriatric Pharmacoepidemiology and Biostatistics and Unit of Geriatric Medicine, IRCCS INRCA (Italian National Research Centre On Aging), 87100 Cosenza, CS, Italy

4 Scientific Direction, IRCCS INRCA (Italian National Research Centre On Ageing), 60124 Ancona, AN, Italy developing COVID-19 pneumonia had bilateral lung lesions $(75.7 \%, 95 \% \mathrm{CI}=65.7-84.5 \%)$ and respiratory failure or acute respiratory distress syndrome (ARDS) occurred in 9.5\% (95\% CI $=5.0 \%, 40.3 \%)$ of patients [2].

As a new infectious disease carrying a high risk of severe course and intensive care unit admission, it is particularly important to explore COVID-19 clinical characteristics, which may help to manage properly its sequelae in the postacute phase. It is worth noting that evidence about pulmonary function tests among COVID-19 patients is currently limited to a trial showing that 6-week respiratory rehabilitation can improve respiratory function, quality of life and anxiety of older patients [3]. Therefore, we aimed at assessing respiratory function at the time of clinical recovery and 6 weeks after discharge in patients surviving to COVID-19 pneumonia.

\section{Methods}

Our study included 13 adult patients with COVID-19 bilateral pneumonia admitted to the respiratory acute care ward at IRCCS INRCA hospital in Merate (Lombardy, Italy), between March 14th and April 14th, 2020. Inclusion criteria were the availability of written informed consent to 
participate in the study and ability to perform pulmonary function tests correctly. The study was approved by the Ethics Committee of the IRCCS INRCA.

COVID-19 bilateral pneumonia was diagnosed by positive polymerase chain reaction (PCR) testing on nasopharyngeal swab and presence of bilateral lung infiltrates on chest $\mathrm{X}$-ray upon admission.

Patient history, body mass index (BMI), smoking habit, signs and symptoms, complete laboratory panel and setting transitions were collected.

Chest high-resolution computed tomography (CT), spirometry, 2-min walking test and arterial blood gas analysis at the time of clinical recovery (i.e. the day before discharge) were included in the study. Clinical recovery was defined by the presence of all of the following: absence of fever for at least $48 \mathrm{~h}, \mathrm{PaO}_{2}$ greater than $60 \mathrm{mmHg}$ on arterial blood gas testing on room air, and negative $\mathrm{C}$-reactive protein (CRP) on two consecutive blood samples performed at least $48 \mathrm{~h}$ apart.

2-minute walking test was performed on room air under the supervision of a respiratory therapist in the patients' room. Nocturnal pulse oximetry was also recorded on room air. PalmSAT 2500 pulse oximeters were used for recordings (Nonin, USA).

Arterial blood gases analysis was performed regularly during hospitalization to monitor oxygen requirements by Cobas b 123 (Roche, Switzerland) point-of-care testing system.

Pulmonary function tests were performed using Microlab portable spirometer (Viasys Healthcare, USA). Forced expiratory volume in the first second $\left(\mathrm{FEV}_{1}\right)$, forced vital capacity (FVC) and $\mathrm{FEV}_{1} / \mathrm{FVC}$ ratio were included in the analysis. For each patient lower limit of normality (LLN) values for $\mathrm{FEV}_{1}, \mathrm{FVC}$, and upper limit of normality (ULN) values fo $\mathrm{FEV}_{1} / \mathrm{FVC}$ were also calculated by Global Lung Function 2012 equations [4]. Correct performance of forced expiration was ensured by medical personnel who observed the patients at security distance to minimize the risk of infection due to droplet spreading. Pulmonary function tests were repeated 6 weeks after discharge.

Descriptive data were presented as mean \pm SD for continuous variables or number (percentage) for categorical ones. Paired data $t$ test was used when appropriate. Statistical analysis was carried out by SPSS V.24 statistical software package (SPSS for Windows V24, SPSS Inc., Chicago, IL, USA).

\section{Results}

Overall, patients enrolled in the study were aged $57.8 \pm 10.0$ years (range $34-73$ years) and almost exclusively male (12 patients, $92.3 \%$ ). Additionally, all patients were no smokers. Fever $(N=13)$, dyspnea $(N=11)$ and cough $(N=10)$ were the most frequently observed symptoms at presentation. Pre-existing comorbidities are reported in Table 1. Patients included in the analysis did not exhibit respiratory comorbidities with the exception of one patient with pre-existing history of asthma. Seven out of 13 patients had BMI $>30 \mathrm{~kg} / \mathrm{m}^{2}$. The average length of hospital stay was $29.5 \pm 9.8$ days.

CT scan at the time of clinical recovery showed persistent multifocal ground glass opacities in 12 patients, crazy paving in 6 patients, linear opacities in 7 patients and consolidation pattern associated to multifocal ground glass opacities in 5 patients.

Interestingly, walked distance was less than $100 \mathrm{~m}$ in only 4 patients, and limited burden of dyspnea and fatigue was observed. Additionally, blood gas analysis showed only mild hypoxemia in 7 patients. Nevertheless, average nocturnal $\mathrm{SaO}_{2}$ was compatible with clinically relevant night-time hypoxemia in 7 out of 13 patients.

Figure 1 shows pulmonary function variables of patients studied. At the baseline, the average $\mathrm{FEV}_{1} / \mathrm{FVC}$ was higher compared to ULN values $(p=0.029)$, while FVC $(p<0.001)$ and $\operatorname{FEV}_{1}(p=0.004)$ were lower compared to respective LLN values in enrolled patients. After 6 weeks, an overall improvement in pulmonary function was observed (see also supplementary Table 1), but FVC was still lower than LLN.

\section{Discussion}

Results of the present case series suggest that COVID-19 pneumonia may result in clinically relevant alterations in pulmonary function tests, with a restrictive pattern in 10 out of 13 patients at the time of hospital discharge. After 6 weeks, pulmonary function improved, but some degree of restrictive alteration still persisted.

Patients surviving to COVID-19 pneumonia may present with a restrictive pulmonary pattern, which is known to be associated with increased risk of life-threatening comorbidities $[5,6]$. While the need of further data with DLCO and plethysmography deserves to be recognized, our results suggest that survivors to COVID-19 pneumonia should be carefully screened for pulmonary function and rehabilitation needs at the end of acute phase, and eventually referred to specific care pathways to monitor and manage clinically relevant sequelae during follow-up.

Our data suggest that pulmonary function needs to be carefully investigated in COVID-19 patients, as it was already done for other atypical pneumonia. Indeed, pulmonary function tests were found to improve significantly in the first 3 months but with no further significant improvement from 3 to 6 months after discharge among survivors to severe influenza A (H1N1) pneumonia [7], and other studies 
Table 1 Demographic and pulmonary function parameters of COVID-19 patients studied

\begin{tabular}{|c|c|c|c|c|c|c|c|c|c|c|c|c|c|c|}
\hline & All patients $(N=13)$ & Pt 1 & Pt 2 & Pt 3 & Pt 4 & Pt 5 & Pt 6 & Pt 7 & Pt 8 & Pt 9 & Pt 10 & Pt 11 & Pt 12 & Pt13 \\
\hline Age & $57.8 \pm 10.0$ & 64 & 55 & 57 & 68 & 73 & 53 & 46 & 65 & 63 & 57 & 34 & 57 & 59 \\
\hline Sex, M & $12(92.3 \%)$ & M & $\mathrm{M}$ & M & M & $\mathrm{F}$ & M & M & M & M & M & M & M & M \\
\hline BMI, kg/m² & $30.5 \pm 5.6$ & 22.6 & 26.6 & 31.5 & 25.2 & 28.1 & 40.6 & 38.6 & 31.7 & 35.3 & 26.1 & 24.8 & 30.7 & 34.8 \\
\hline \multicolumn{15}{|l|}{ Comorbidities } \\
\hline Hypertension & $3(23.1 \%)$ & $\mathrm{N}$ & $\mathrm{N}$ & $\mathrm{N}$ & $\mathrm{N}$ & $\mathrm{N}$ & $\mathrm{N}$ & $\mathrm{N}$ & $\mathrm{Y}$ & $\mathrm{Y}$ & $\mathrm{N}$ & $\mathrm{N}$ & $\mathrm{Y}$ & $\mathrm{N}$ \\
\hline Heart failure & - & $\mathrm{N}$ & $\mathrm{N}$ & $\mathrm{N}$ & $\mathrm{N}$ & $\mathrm{N}$ & $\mathrm{N}$ & $\mathrm{N}$ & $\mathrm{N}$ & $\mathrm{N}$ & $\mathrm{N}$ & $\mathrm{N}$ & $\mathrm{N}$ & $\mathrm{N}$ \\
\hline Coronary artery disease & $1(7.7 \%)$ & $\mathrm{N}$ & $\mathrm{N}$ & $\mathrm{N}$ & $\mathrm{N}$ & $\mathrm{N}$ & $\mathrm{N}$ & $\mathrm{N}$ & $\mathrm{Y}$ & $\mathrm{N}$ & $\mathrm{N}$ & $\mathrm{N}$ & $\mathrm{N}$ & $\mathrm{N}$ \\
\hline COPD & - & $\mathrm{N}$ & $\mathrm{N}$ & $\mathrm{N}$ & $\mathrm{N}$ & $\mathrm{N}$ & $\mathrm{N}$ & $\mathrm{N}$ & $\mathrm{N}$ & $\mathrm{N}$ & $\mathrm{N}$ & $\mathrm{N}$ & $\mathrm{N}$ & $\mathrm{N}$ \\
\hline Asthma & $1(7.7 \%)$ & $\mathrm{N}$ & $\mathrm{Y}$ & $\mathrm{N}$ & $\mathrm{N}$ & $\mathrm{N}$ & $\mathrm{N}$ & $\mathrm{N}$ & $\mathrm{N}$ & $\mathrm{N}$ & $\mathrm{N}$ & $\mathrm{N}$ & $\mathrm{N}$ & $\mathrm{N}$ \\
\hline Diabetes & $1(7.7 \%)$ & $\mathrm{N}$ & $\mathrm{N}$ & $\mathrm{N}$ & $\mathrm{N}$ & $\mathrm{N}$ & $\mathrm{Y}$ & $\mathrm{N}$ & $\mathrm{N}$ & $\mathrm{N}$ & $\mathrm{N}$ & $\mathrm{N}$ & $\mathrm{N}$ & $\mathrm{N}$ \\
\hline Atrial fibrillation & $1(7.7 \%)$ & $\mathrm{N}$ & $\mathrm{N}$ & $\mathrm{N}$ & $\mathrm{Y}$ & $\mathrm{N}$ & $\mathrm{N}$ & $\mathrm{N}$ & $\mathrm{N}$ & $\mathrm{N}$ & $\mathrm{N}$ & $\mathrm{N}$ & $\mathrm{N}$ & $\mathrm{N}$ \\
\hline Dementia & $1(7.7 \%)$ & $\mathrm{N}$ & $\mathrm{N}$ & $\mathrm{N}$ & $\mathrm{Y}$ & $\mathrm{N}$ & $\mathrm{N}$ & $\mathrm{N}$ & $\mathrm{N}$ & $\mathrm{N}$ & $\mathrm{N}$ & $\mathrm{N}$ & $\mathrm{N}$ & $\mathrm{N}$ \\
\hline Stroke & $1(7.7 \%)$ & $\mathrm{N}$ & $\mathrm{N}$ & $\mathrm{N}$ & $\mathrm{Y}$ & $\mathrm{N}$ & $\mathrm{N}$ & $\mathrm{N}$ & $\mathrm{N}$ & $\mathrm{N}$ & $\mathrm{N}$ & $\mathrm{N}$ & $\mathrm{N}$ & $\mathrm{N}$ \\
\hline CKD & - & $\mathrm{N}$ & $\mathrm{N}$ & $\mathrm{N}$ & $\mathrm{N}$ & $\mathrm{N}$ & $\mathrm{N}$ & $\mathrm{N}$ & $\mathrm{N}$ & $\mathrm{N}$ & $\mathrm{N}$ & $\mathrm{N}$ & $\mathrm{N}$ & $\mathrm{N}$ \\
\hline \multicolumn{15}{|l|}{ Blood gas analysis } \\
\hline $\mathrm{PaO}_{2}, \mathrm{mmHg}$ & $68.8 \pm 7.1$ & 67.2 & 76.8 & 80.1 & 67.0 & 62.8 & 76.0 & 66.0 & 73.0 & 60.0 & 68.5 & 74.1 & 68.7 & 57.2 \\
\hline $\mathrm{PaCO}_{2}, \mathrm{mmHg}$ & $35.5 \pm 3.6$ & 34.6 & 39.9 & 35.3 & 37.0 & 35.4 & 28.0 & 37.0 & 31.0 & 34.6 & 40.7 & 39.2 & 37.0 & 31.9 \\
\hline $\mathrm{SaO}_{2}, \%$ & $95.9 \pm 1.7$ & 95.0 & 96.7 & 97.5 & 99.0 & 94.0 & 98.0 & 95.0 & 96.0 & 93.0 & 95.6 & 96.3 & 95.0 & 94.2 \\
\hline $\mathrm{HCO}_{3}, \mathrm{mmol} / \mathrm{l}$ & $24.5 \pm 1.5$ & 24.3 & 25.5 & 22.9 & 26.1 & 22.0 & 24.5 & 24.7 & 22.6 & 26.0 & 26.9 & 25.3 & 24.1 & 23.8 \\
\hline $\mathrm{pH}$ & $7.4 \pm 0.0$ & 7.46 & 7.42 & 7.43 & 7.46 & 7.42 & 7.51 & 7.44 & 7.45 & 7.49 & 7.43 & 7.42 & 7.43 & 7.46 \\
\hline \multicolumn{15}{|l|}{ Functional status } \\
\hline 2-min walked distance, $\mathrm{m}$ & $134.4 \pm 61.6$ & 82 & 140 & 140 & 70 & 100 & 133 & 154 & 84 & 168 & 80 & 294 & 168 & n.a \\
\hline Borg scale dyspnea & $2.5 \pm 1.8$ & 1 & 3 & 1 & 4 & 2 & 2 & 6 & 4 & 4 & 0 & 0 & 3 & n.a \\
\hline Borg scale fatigue & $1.5 \pm 1.7$ & 1 & 3 & 0 & 0 & 0 & 2 & 5 & 0 & 3 & 1 & 0 & 3 & n.a \\
\hline Nocturne $\mathrm{SaO}_{2}, \%$ & $91.2 \pm 1.8$ & 92.5 & 93.5 & 90.7 & 91.0 & 90.8 & 92.0 & 87.0 & 91.3 & 89.5 & 90.3 & 94.1 & 90.9 & 91.4 \\
\hline
\end{tabular}

Data are means \pm SD or number (percentage)

$C O P D$ chronic obstructive pulmonary disease, $C K D$ chronic kidney disease, $n . a$. not able to perform

showed a complete normalization of pulmonary function 6 months after H1N1-related ARDS [8]. At variance, about $80 \%$ of survivors to ARDS not caused by influenza A H1N1 had reduced diffusing capacity, $20 \%$ had airway obstruction, and 20\% had restrictive pattern 12 months after recovery [9].

If our data will be confirmed by a more comprehensive diagnostic assessment, it will likely be necessary to rethink the pneumology services with an increase in the availability of respiratory rehabilitation units in the areas most violently affected by the pandemic. The recent demonstration that sixweek respiratory rehabilitation can effectively improve respiratory function in older patients with COVID-19 [3] is in keeping with this view.

The small sample size and the simple spirometric approach are main limitations of the present study. Additionally, pulmonary function tests before COVID-19 infection are not available for our patients. Nevertheless, our results may represent an important first step in the knowledge of COVID-19 consequences in terms of pulmonary function.

In conclusion, COVID-19 pneumonia may result in significant alterations in lung function, with a mainly restrictive pattern, partly persisting at 6 weeks after recovery. Further studies are needed to confirm this observation on wider populations and with a more detailed diagnostic work-up. However, given the potential implications of spirometric restrictive patterns in terms of quality of life and independency of patients [10], it will be necessary to prevent the tsunami of post-COVID-19 patients from catching healthcare systems unprepared again after the pandemic.

\section{Availability of data and material}

Data are locally available for participating researchers and stored in the data repository of the IRCCS INRCA. 
Fig. 1 Pulmonary function tests at the time of clinical recovery (i.e. the day before discharge) and 6 weeks after discharge in the patients studied
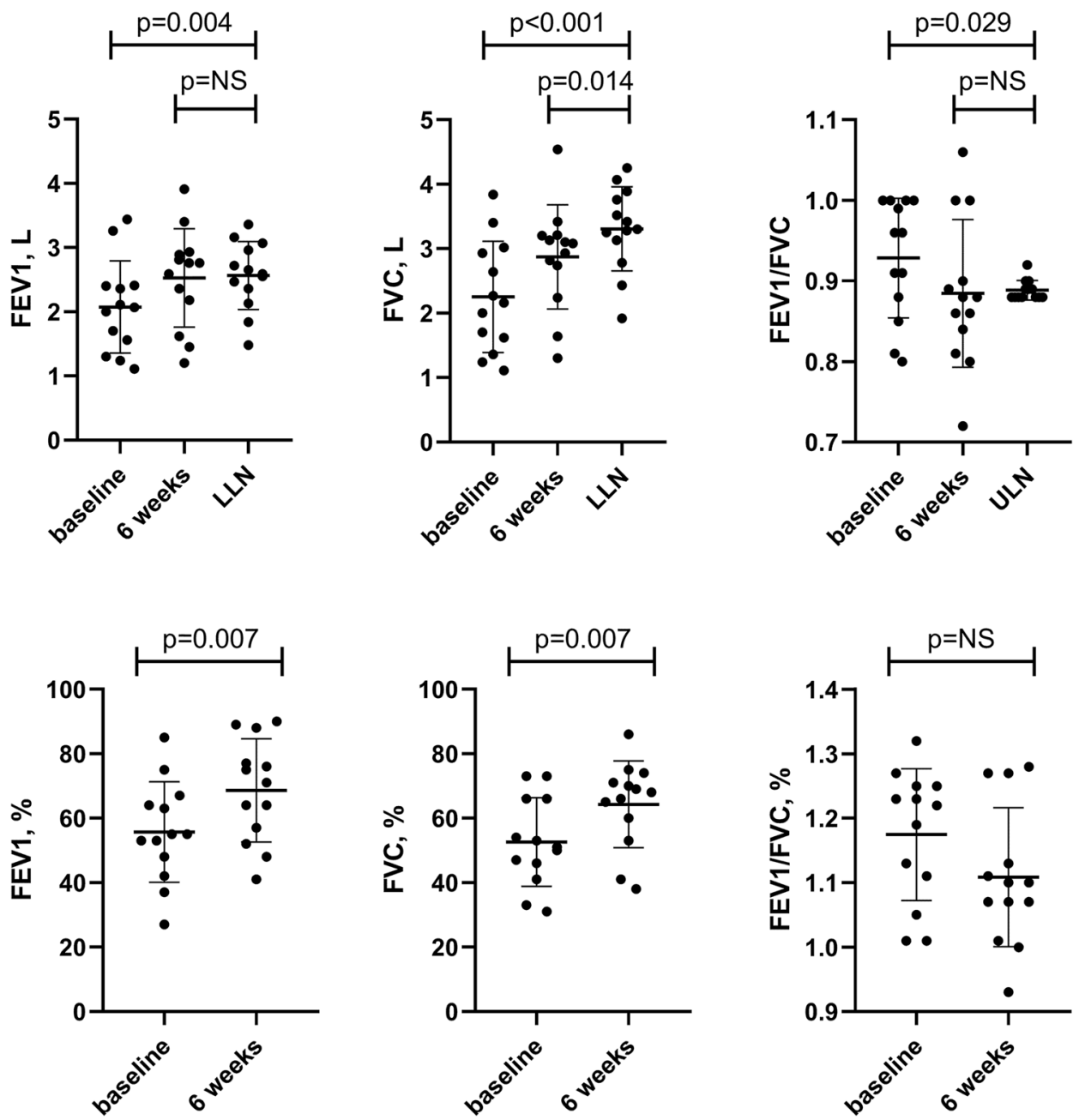

Author contributions Study design: AF, CM, DC; Literature Search: AC, MDR, LS; Data Collection: AF, CM AB, NB, SL, SM, DRB, DC; Data Analysis: AC, MDR, LS; Drafting paper: AF, CM, AC, MDR, LS, FL; Manuscript Reviewing-all authors.

Funding None.

\section{Compliance with ethical standards}

Conflict of interest All Authors declare to have no conflict of interest/ competing interest to disclose with this manuscript.

Ethics approval The study was approved by the Ethics Committee of the Italian National Research Center on Aging (IRCCS INRCA), study \#20008/2020 and deliberation \#141/DGEN/2020.

Consent to participate All patients signed a written informed consent to be enrolled in the study.

\section{References}

1. WHO-coronavirus disease (COVID-19) Situation report-137, June 5, 2020. https://www.who.int/emergencies/diseases/novel-coron avirus-2019/situation-reports. Accessed 16 May 2020
2. Zhu J, Ji P, Pang J, Zhong Z, Li H, He C, et al. Clinical characteristics of 3062 COVID-19 patients: a meta-analysis. J Med Virol. 2020; . https://doi.org/10.1002/jmv.25884.

3. Liu K, Zhang W, Yang Y, Zhang J, Li Y, Chen Y. Respiratory rehabilitation in elderly patients with COVID-19: a randomized controlled study. Complement Ther Clin Pract. 2020;39:101166.

4. Quanjer PH, Stanojevic S, Cole TJ, Baur X, Hall GL, Culver BH, et al. Multi-ethnic reference values for spirometry for the 3-95-year age range: the global lung function 2012 equations. Eur Respir J. 2012;40:1324-43.

5. Guerra S, Sherrill DL, Venker C, Ceccato CM, Halonen M, Martinez FD. Morbidity and mortality associated with the restrictive spirometric pattern: a longitudinal study. Thorax. 2010;65:499-504.

6. Scarlata S, Pedone C, Fimognari FL, Bellia V, Forastiere F, Incalzi RA. Restrictive pulmonary dysfunction at spirometry and mortality in the elderly. Respir Med. 2008;102:1349-54.

7. Hsieh MJ, Lee WC, Cho HY, Wu MF, Hu HC, Kao KC, et al. Recovery of pulmonary functions, exercise capacity, and quality of life after pulmonary rehabilitation in survivors of ARDS due to severe influenza A (H1N1) pneumonitis. Influenza Other Respir Viruses. 2018;12:643-8.

8. Toufen C Jr, Costa EL, Hirota AS, Li HY, Amato MB, Carvalho CR. Follow-up after acute respiratory distress syndrome caused by influenza a (H1N1) virus infection. Clin (Sao Paulo). 2011;66:933-7.

9. Orme J Jr, Romney JS, Hopkins RO, Pope D, Chan KJ, Thomsen $\mathrm{G}$, et al. Pulmonary function and health-related quality of life in 
survivors of acute respiratory distress syndrome. Am J Respir Crit Care Med. 2003;167:690-4.

10. Guerra S, Carsin AE, Keidel D, Sunyer J, Leynaert B, Janson C, et al. Health-related quality of life and risk factors associated with spirometric restriction. Eur Respir J. 2017;49:1602096. https://doi. org/10.1183/13993003.02096-2016. 